\title{
VI
}

\section{MARRIAGE AND GONORRHOEA}

Discussion after an Address by Mr. Johnston Abraham.

The Chairman (Colonel Harrison) said members would feel greatly indebted to Mr. Abraham for his extraordinarily interesting and lucid exposition of the subject. He had himself found the historical portion of it especially interesting. It was always well to know what our predecessors did. Such knowledge engendered some degree of humility in us, as we ourselves would be in the same position before very long, and might be as much the subject of criticism. He hoped that we should be dealt with as kindly as Mr. Abraham had dealt with our predecessors. He would reserve any further remarks he had to make until the end of the discussion.

Dr. PEDRoso said he thought the subject of gonorrhoa had been studied too much from the local standpoint. Many interesting points in relation to the disease could be explained on biological grounds. One of these was the lowered resistance to urethritis. Certain kinds of microbes required "soil" of a certain chemical composition for their development, and that was why certain people suffered from the disease in greater virulence than did others. He had studied this subject from the biochemical standpoint, and he had observed that in cases in which it was impossible to cure the discharge there was some defect in expiration. All the living organism required to bring about a better state of things was increased oxygen. There seemed to be a close relationship between the virulence of gonorrhoea and the amount of gas in the blood. The gonococcus required a certain pressure of carbon-dioxide for its existence, and it might be an increased pressure of $\mathrm{CO}_{2}$ in the patient which gave him an extra virulent attack.

For some years he had been trying to ascertain why exercise and the indulgence in alcohol interfered with the success of treatment, and he found that these factors brought about an excess of carbon-dioxide in the blood, 


\section{BRITISH JOURNAL OF VENEREAL DISEASES}

giving to the organism a better medium for its growth. Where the ordinary treatment was not very effective, by improving the respiration and carefully regulating exercise, the discharge was much improved.

Dr. Hanschell : Mr. Abraham had rather stressed the point that some special strain of gonococcus vaccine, known-presumably empirically-to be effective, was necessary for provocative injection in testing for gonococcal cure. Personally he had found any vaccine, e.g., typhoid or $B$. coli, given intravenously, and sterilised milk given intramuscularly, provoke a urethral reaction with discharge of gonococci, in uncured cases, far more constantly than by giving even very large doses of killed gonococci intramuscularly or subcutaneously. One should aim at producing a sharp febrile reaction. It was not always necessary to put the patient to bed for this.

With regard to Mr. Abraham's contention that staphylococcal and other non-gonococcal infections of the male urethra were contagious for the woman, surely this must be true only for certain, happily very rare, strains not yet identified. He had known men with non-gonococcal, though certainly post-gonococcal, infections of the urethra, such as staphylococcal and coliform, marry. Their children were born with healthy conjunctivæ, and after a period of years their wives had remained unaffected, although the infection, with occasional slight discharge and always threads in the urine, was still present in their husbands.

After all, even in cleanly men and women, prepuce and vulva must frequently, if not habitually, harbour these microbes.

Dr. B. B. Sharp said that when people had a nonspecific urethritis he had thought they were safe, but since he formed that belief he had come across one or two cases in which non-gonococcal urethritis was developed following sexual congress, and he therefore assumed that the infection had been caught from a partner in that way. Those cases were very difficult to cure, $\epsilon$ specially those in which the man had a slight discharge, with pus cells and secondary organisms, and in which, with the urethroscope, one found a polypoid condition in the ristal part of the urethra. For these cases he had tried various treatments : autogenous vaccines, and even touching up each polypoid excrescence with nitrate of silver and with 


\section{MARRIAGE AND GONORRHEA}

the electric cautery. The only means which gave partial success was ionisation of the urethra with a zinc rod in a solution of zinc sulphate, using a very weak current. The man to whom these remarks applied was wishful to marry, and he would like Mr. Johnston Abraham to say whether it would be safe for him to do so.

Mr. W. F. FEDDEN said he was interested to hear Mr. Abraham refer to the question of other infections of the urethra, because, whether those other infections were primary or whether they were secondarily implanted on to the gonorrhœal infection, they were the most difficult conditions to treat by any method. Of the later infections he had been chiefly struck by the streptococcal, as in both sexes this was responsible for serious complications. $\mathrm{He}$ agreed that when one found pus cells and organisms, especially streptococci, it was not safe for such patient to marry. He would be very glad to hear from Mr. Abraham any " tips " concerning the cure of such cases. He agreed as to the difficulty of saying when a female was cured of gonorrhœa. Some were apparently cured, then they relapsed, even though all clinical signs had been absent for some considerable time.

Squadron-Leader T. C. Morton asked whether a nonspecific primary urethritis, apart from one due to $B$. coli, ever led to epididymitis? He had seen one case of $B$. coli urethritis, and that he refrained from treating locally. He used alkalis, then urotropine, but the disease spread up to the kidney from the urethra and the man was very acutely ill. He eventually recovered.

Major E. C. Lambkin thanked Mr. Abraham for his interesting paper. Some cases of non-specific urethritis were seen in the Army, and he was interested in the last Annual Report of the Army, in which Major White reported from Egypt a tremendous increase in the number of cases of non-specific urethritis there. His own feeling in regard to urethritis was to first suspect gonorrhœa. The gonococcus was a great precursor of damage to other tissues, and one did not know how long a delay may have occurred before a man presented himself for treatment. Many mild cases of the disease seemed to get rid of the active disease but were left with a gleet, and all the organisms one could find were diphtheroids or staphylococci. Eventually gonococci would be found if one were sufficiently patient: he had found them after a daily 


\section{BRITISH JOURNAL OF VENEREAL DISEASES}

examination for six weeks. These cases were found to have epididymitis or prostatitis.

With regard to tests of cure in the male, the giving of beer and pickles and the application of silver nitrate had been mentioned. He, like Mr. Abraham, did not like using silver nitrate solutions on the urethra. By it one might not provoke discharge, but it might cause shreds and hazy urine to appear.

At Woolwich for some time medical officers at the clinic had been injecting a gonococcal endotoxin into the urethra. It was practically a gonococcus vaccine. It was a twenty-four-hour growth of gonococcus washed off in alkali, then frozen and thawed for about a week, with the idea of absolutely lysing all the gonococci and getting all the endotoxin of the germ. That was made up to $25^{\circ}$ million per c.c., and was injected into the urethra. It proved to be an almost infallible provocative. He had often examined the urethra with the urethroscope without seeing a single focus of disease, and with the sound could feel practically nothing except that there was a focus in the anterior urethra. If the injection were held in some time, nearly always a discharge would be caused, showing it was gonococcal. One might have to wait four or five days before the man got his provocation from the endotoxin. At the same time he gave a gonococcal vaccine. That was their routine test before discharging a man as cured.

He had been interested in the remarks about the $\mathrm{CO}_{2}$ content. It was found that by giving bigger dosès of alkali the cases were being improved. As much as 960 grs. of sodium bicarbonate a day was given, and it was a tremendous help in curing acute cases. In an atmosphere of $\mathrm{CO}_{2}$ the growth of the gonococcus was increased. Stimulation by $\mathrm{CO}_{2}$ had now been cut out, and sodium phosphate was substituted with better results.

The Chairman (Colonel Harrison) said it had been nice to listen to such a stimulating discussion. Much had been said on the question of the importance of secondary infections. During the discussion he had found himself agreeing first with one side and then with the other. He recognised that in the secretion of patients with secondary infection following gonorrhœa there might be virulent streptococci which could make headway against normal mucous membrane, but it was necessary to remember that 


\section{MARRIAGE AND GONORRHEA}

in the preputial sac, as also around the vulva, streptococci, staphylococci and $B$. coli were found naturally, and the important question from the point of view of marriage was the ability of these organisms to break through normal mucous membrane. He thought that if the mucous membrane was intact, the organisms commonly found in secondary infections had very little power against it, but if the resistance of the membrane had been broken down previously by the gonococcus, secondary organisms were able to gain a good foothold. He had had experience of primary infection with such organisms in cases in which there had been no previous attack of gonorrhœa, and they had usually been cured by a few irrigations with such a preparation as mercury oxycyanide. On the other hand, he had had a bitter experience of secondary infections following gonorrhœa, and he agreed also that the condition in which the anterior urethra seemed to be studded with sago grains was most resistant to treatment.

He was not surprised at the old statement that a man could contract gonorrhœa from a healthy female, because he had had experience of females with no sign of inflammation in the cervix and in whom the secretion seemed to be healthy, of normal quantity, and containing no pus cells, yet he had been able to cultivate gonococci from it. Such cases emphasised the importance of laboratory methods in tests of cure. It would be gathered from what had been said how wide must be the foundation on which judgment as to cure must be based.

Dr. Hanschell's remarks reminded him of the test of cure by means of Aolan, injected intradermally. This produced a urethral discharge, in which gonococci were more likely to be found than when specimens were taken from the surface of the quiescent mucous membrane.

He agreed with what had been said as to silver nitrate. He had no part in causing it to be recommended in the Ministry's tests of cure. These tests were the recommendations of a committee of experts whom the Ministry of Health called to their assistance. He did not himself use silver nitrate.

On the question of the comparative value of smears and cultures, he agreed one might find the one negative and the other positive from the same patient, but his feeling favoured cultures; these must, however, be properly 


\section{BRITISH JOURNAL OF VENEREAL DISEASES}

taken and planted on good medium if reliable results were to be obtained.

With regard to the complement-fixation test at St. Thomas's Hospital, it had been found sometimes that the complement-fixation reaction had been the only indication of a persistent gonococcal infection which had been proved weeks later by both smears and cultures.

A persistent positive complement-fixation reaction could not be ignored, and in the face of it he hesitated, without further stringent tests, to allow the patient to marry.

Mr. Johnston Abraham, in reply, said he felt much obliged to all the speakers for the very nice things they had said about his paper. Dr. Pedroso's suggestion might account for exercise apparently making patients worse. $\mathrm{He}$ had been interested to hear Dr. Hanschell say that any vaccine would cause this reaction, and he, the speaker, supposed it must do it by lowering the resistance of the body. (Dr. HANSCHELl : You must have enough to provoke a general reaction.) He had not tried any except gonococcal, and he was careful not to use too much of that. If one gave an injection and the patient came and said the discharge was worse, he was not happy about it, because by producing a negative phase one was making the patient worse.

Infection by secondary organisms was a subject that most of the speakers had referred to, and it was a serious matter. He had seen several people in the profession who had had secondary organismal infections, and it was almost impossible to clear them up. He had lost one or two friends by giving them permission to get married. There occurred a persistent infection, lasting for years, and nothing seemed to give them benefit except the method of ionisation on the system of Russ. Women with streptococci in the cervix were often sterile. If one had them dilated and curetted one might set up a marked inflammatory reaction, and there might even be peritonitis. The $B$. coli did not seem to matter a great deal in the woman's urethra. He thought the kind of re-infection which Colonel Ffrench mentioned often occurred, thus producing the vicious circle he spoke of. It was usually the cervix which one must look at specially and treat. But it was often forgotten that the female urethra contained organisms, and often these were still present when 


\section{MARRIAGE AND GONORRHEA}

the cervical condition had been cleared up. Too much attention therefore must not be paid to the cervix to the exclusion of other sites of infection.

With regard to the medico-legal aspect, one should not omit to guard oneself when giving an opinion by the formula "To the best of my belief."

He did not think cases of infection with secondary organisms in the male were always gonococcal in the first instance. Many were cases where no gonococci ever had been found ; and in some instances later it had been discovered that the man had infected his wife with those same organisms, much to his distress. The more he saw of these cases the less inclined he was to give permission to marry if there was pus or any organisms still present. Any form of urethritis must be considered a bar to marriage.

He had been interested in the form of local injection described by Major Lambkin. That sounded good, and he would like to try it.

He expressed his sincere thanks to members for their patient hearing and exhibited some old books on the subject of gonorrhœa. 